University of Nebraska - Lincoln DigitalCommons@University of Nebraska - Lincoln

To Improve the Academy

Professional and Organizational Development

Network in Higher Education

1991

\title{
Gender and Racial Differences among a Research University Faculty: Recommendations for Promoting Diversity
}

Deborah Olsen

Follow this and additional works at: http://digitalcommons.unl.edu/podimproveacad

Part of the Higher Education Administration Commons

Olsen, Deborah, "Gender and Racial Differences among a Research University Faculty: Recommendations for Promoting Diversity" (1991). To Improve the Academy. 225.

http://digitalcommons.unl.edu/podimproveacad/225

This Article is brought to you for free and open access by the Professional and Organizational Development Network in Higher Education at DigitalCommons@University of Nebraska - Lincoln. It has been accepted for inclusion in To Improve the Academy by an authorized administrator of DigitalCommons@University of Nebraska - Lincoln. 


\section{Gender and Racial \\ Differences among a Research University Faculty: Recommendations for Promoting Diversity}

\section{Deborah Olsen}

Indiana University, Bloomington

There is currently an unprecedented level of interest in recruiting and retaining women and minority faculty, groups traditionally underrepresented in the academy. Driven in part by demographic changes in the labor force and predictions of a shrinking pool of faculty applicants, universities and colleges have begun to reassess the campus climate for women and minorities. A handful of major universities, such as Stanford and the University of Michigan, have recently undertaken substantial initiatives to expand and promote the work of women and minority faculty at their institutions. However, it is still true that the majority of women and minorities remain concentrated at less prestigious, two-year and four-year colleges and at the lower end of the faculty ranks (Lomperis, 1990; Menges \& Exum, 1983).

The fact that gender/racial status and institutional affiliation/academic rank are often confounded becomes particularly important when attempting to interpret current research on the academic performance and role interests of women and minority academics-research that suggests lower research productivity, a heavy teaching orientation, and substantial commitment to institutional service (Carnegie Foundation, 1990; Finkelstein, 1984; Menges \& Exum, 1983; Simeone, 1987). One way to disentangle the effects of institutional type and rank from those more directly attributable to gender and race is to examine the experience of faculty in a more homogeneous 
academic environment - in particular, a research-oriented, doctoral-degree granting institution that selects faculty based largely on their interest and performance in the area of research. Though generalizations based on data from such a sample would be limited in nature, differences found among white male, white female, and minority faculty should provide useful information about race- and gender-based differences among faculty groups with similar professional demands.

This paper describes interviews conducted with 146 minority, white female, and white male tenure-track faculty from a large, public research university. The study was carried out to provide a broad and systematic basis for policy and program recommendations for the recruitment and retention of women and minority faculty. By speaking with faculty we hoped to understand better what aspects of the faculty experience are common to all faculty at a major research university, and what features of the experience differ by race and gender. During the one-to-three hour interviews we spoke with faculty about research, teaching, and service; relationships with colleagues and with the university; and about the inevitable conflicts between academic and personal lives. The results suggest a picture of faculty who overlap broadly in their expectations, goals, and achievements, but who also, despite intense socialization and selectivity pressures, differ in significant ways. Understanding the differences among faculty groups is particularly useful to faculty developers, whose task is to help all faculty perform to their fullest, reaching a successful balance between personal proclivities and interests, and institutional expectations.

\section{Method}

\section{Sample}

Of the 146 tenure-track faculty interviewed for the study, $29 \%$ were white males, $32 \%$ were members of an underrepresented minority (AfricanAmerican, Hispanic, or Native American), and 39\% were white females. Minority faculty comprise approximately $4 \%$ of faculty at Bloomington (a figure comparable to that found at other public research universities, Russell et al., 1990) and virtually all minority faculty on campus at the time were interviewed. In 1989-90, women constituted about $20 \%$ of tenure-track faculty at Bloomington. Approximately $90 \%$ of all faculty contacted, regardless of subsample membership, were willing to participate. Faculty were drawn from the College of Arts and Science, the School of Education, and the Business School, and represented all faculty ranks. The School of Education and the School of Business were included because women and 
Blacks have traditionally been better represented in education and underrepresented in business. Approximately $25 \%$ of each subsample held some type of formal administrative position (e.g., director, chair, dean), so there was no obvious difference in the three groups' level of service based on formal administrative responsibilities.

\section{Measures}

Faculty were contacted by the Office of Academic Affairs and invited to participate in an hour to hour-and-a-half interview on faculty career development. Faculty were not aware that matters of race or gender were at issue and, in fact, few questions dealt specifically with these topics. By inquiring into the more general aspects of faculty development, we were able to address key questions raised by the literature on women and minority faculty and yet not bias participants' responses. Our findings thus emerged fairly spontaneously from faculty comments.

Faculty responses were gathered using two different instruments, a semi-structured interview schedule and a questionnaire. Both instruments were based on measures developed in past studies by the Office of Academic Affairs (Sorcinelli, 1988). The interview covered the following general areas: career path, major responsibilities and interests (research-teaching-service), balancing work roles, balancing work and personal life, performance evaluation and criteria, greatest satisfactions, stresses and successes, career plans, and women's and minority issues. The Faculty Career Questionnaire included measures of "facet-specific" and "global" job satisfaction, work stress, satisfaction with nonwork life, and the balance between work and nonwork life. In addition, faculty were asked what kinds of programs would contribute most to their own professional development.

The approach taken in the study was a blend of ethnography (an open-ended accounting of responses and behavior) and standard survey techniques. Instead of asking one or two questions about an area or issue, we asked a series of related questions, hoping to find patterns of response across measures, across topics, and across questions. These methods helped add a richness to our data. However, one caveat about the data is also in order. In reviewing the findings, readers should remember that data reflect faculty perceptions of career, work environment, university governance, and colleagues. For much of the data collected there is no other source than the faculty themselves. As Bowen and Schuster (1986) note, "[ $t]$ he condition of the American professoriate is only in part discernible from the measurably tangible aspects of campus life. The faculty condition cannot be understood apart from the faculty's own perception of its condition"(p. 138). At the same 
time perceptions may be biased, affected by historical or personal events. Study results reported below focus on trends of sufficient magnitude and consistency that it is reasonable to assume a relatively high level of consensus among faculty and faculty subgroups.

\section{Results and Discussion}

\section{Career path}

A growing body of literature suggests that women and minority faculty start their careers at a critical disadvantage because of a systematically different socialization experience (see e.g., Clark \& Corcoran, 1986; Justus, Freitag, \& Parker, 1987; Simeone, 1987). Frequently cited, for example, is the absence of a mentor or sponsor in the early career of women and minority Ph.D.s. Earlier research at Indiana University also suggests that the values and expectations individuals hold when they decide upon an academic career and the course their graduate training and early career takes, are factors that exercise a long-term impact on career development (Sorcinelli \& Gregory, 1987). In this study, wide differences were found in the career paths and expectations of the three faculty groups, differences that were minimized but not eliminated by the professional socialization process.

On the whole, women and minority faculty tended to define their interest in a discipline as early or earlier than white male faculty, but did not consider an academic career until much later, often after the start of graduate school or in the early part of their career. For white men, interest in a field of study and the decision to pursue that interest academically were much more closely linked, with about half of all white men deciding upon a faculty career by the end of their undergraduate years.

Although virtually all faculty reported having been good students and intellectually engaged by academic work, women and minority faculty felt they were less often encouraged to pursue graduate training and were less likely to consider it a realistic career option. Their relatively late commitment to academe appeared to reflect not so much ambivalence as a difficult process of defining a faculty position as a professional possibility. Evidence from the study also suggests that, having once decided upon an academic career, women and minority faculty still held markedly different expectations from their male counterparts of the world they were about to enter. Of the three groups, white male faculty were the only ones clear at the outset of their graduate training about wanting a faculty position at a research university (about a quarter of women were even unsure they wanted a faculty position). Furthermore, white men were more likely to cite "a desire to do research" as 
a key professional incentive, while women and especially minority faculty were more likely to report a desire to teach. Interestingly, white males were almost twice as likely as other faculty to mention an academic lifestyle (freedom, security) as influencing their commitment to an academic career. Perhaps because women and minority faculty were somewhat more naive entering graduate school, or perhaps because they had more family and community commitments, both groups tended to experience more interruptions in their career than white male faculty, the only group with over half reporting a fairly linear career trajectory.

Findings with regard to the mentoring of women and minority faculty were encouraging, with mentoring occurring at a much higher rate $(65 \%$ 75\%) than might be expected from the literature. Approximately one-third of women and minority faculty had same-sex or same-race mentors. Over half of all three faculty groups appeared to receive substantial assistance from their mentors when seeking jobs or other sorts of professional opportunities. At the same time, data suggest that the mentoring experience may have been somewhat different for the three groups. Perhaps most significantly, women and minority faculty reported less support developing specific projects and skills than did white male colleagues. These findings suggest a supportive but somewhat more distant working relationship between women and minorities and their white male mentors, but further examination is required. White women were more likely than white men to see their mentors as role models, and minority faculty were more likely to see minority than white mentors as role models.

\section{Major responsibilities and role interests}

A large and burgeoning literature exists on gender- and race-related differences in the research productivity, teaching load, and service responsibilities of faculty. Although investigations into research productivity appear equivocal, there is a fairly good consensus that women carry heavier teaching loads and teach less at the graduate level, and that women and minorities are extensively involved in service activities on their campus (Carnegie Foundation, 1990; Elmore \& Blackburn, 1983; Finkelstein, 1984; Justus, Freitag, \& Parker, 1987; Menges \& Exum, 1983; Simeone, 1987; Silver, Dennis \& Spikes, 1988). In our interviews, we felt that attempts to quantify and compare different aspects of a faculty member's experience were important, but needed to be interpreted in light of the meaning and value faculty attach to the various responsibilities they shoulder. We were thus concerned about determining what aspects of research, teaching, and service were most satisfying and which most unsatisfying to the three groups of faculty; what 
they perceive as their greatest needs; and how, given different sets of satisfactions and needs, faculty negotiate the various demands on their time and energy. We also felt it was important to understand how faculty perceive the university's expectations of them and how these expectations influence the balance ultimately struck.

Research. Faculty spend one-third or more of their time carrying out research (Table 1). Consistent with white males' earlier, more focused research orientation, they appeared to spend more time than other groups on research, though differences did not reach statistical significance. Overall, faculty were quite satisfied with the quality of their own research, their knowledge of their field, their research skills, and their equipment and facilities. Somewhat surprisingly, it was white male faculty who were least satisfied with the amount of research they carry out and publish. Given the research emphasis in this group, it is quite possible, however, that these findings reflect a discrepancy between quite respectable actual academic attainments and a very high level of expectation. Minority faculty were the group least satisfied with their ability to secure research funding, and they indicated that internal support was of the first importance to their research. Women were least satisfied with their statistical and computer skills. The greatest dissatisfaction for all three groups was with release time for research and funds for travel to professional conferences.

Respondents' answers indicated that departments are satisfying and supportive environments for research. Faculty were consistently more than moderately satisfied with their chairpersons, graduate students, and colleagues. Furthermore, about a third of white male and female faculty cited faculty colleagues or graduate students as the factor most important to their research.

It seemed possible that a critical difference among the three subsamples might be the strategies they use to accomplish research. Such strategies are

\section{TABLE 1}

Mean Percentage of Time Spent in Research, Teaching, \& Service

White Male

$\%$ time research

$\%$ time teaching

$\%$ time service
$41 \%$

$34 \%$

$25 \%$
Minority*

$34 \%$

$34 \%$

$30 \%$
White Female

$36 \%$

$39 \%$

$26 \%$

*Note. Percentages do not capture a small number of minority faculty $(2 \%)$ indicating they spend a percentage of their time on "other" activities (i.e., not research, teaching, or service). 
more or less effective in gaining time and resources and exercise a differential impact on other areas of faculty responsibility. As anticipated, some strategies were used almost universally: faculty work nights and weekends and try to set aside summers for research. Faculty also more consistently avoid unscheduled contact with colleagues than with students to gain research time.

White female faculty appeared to use two primary strategies to make time for research: (1) establishing a teaching schedule that allows two to three hour blocks of time or whole days for research and (2) minimizing nonessential uses of time, e.g., skipping lunch and colloquia, and avoiding casual conversation. Minority members, like women, attempt to establish blocks of time for research. Of the three subsamples, minorities were the least likely (30\% vs. $60 \%$ ), however, to limit teaching time and to refuse service commitments outside the department to accommodate research. Yet, minority faculty do not simply surrender research time to teach; approximately $60 \%$ of minority faculty were unwilling to modify their research goals in the face of other demands. All three faculty groups felt excellence in research is and should be of extreme importance to tenure and review decisions.

Teaching. There were no significant differences among the three subsamples in terms of overall courseload or the number of new courses taught. Consistent with the literature, however, white women did appear to teach more introductory courses and, in particular, fewer graduate courses than white men. Figures for percentage of time spent teaching (Table 1) hovered around one-third for all groups (women's estimate being only slightly higher).

As in the case of research, faculty felt quite satisfied overall with their skills, their content expertise, and their readiness for assignments. Nevertheless, of the three groups, minority faculty were most satisfied with their students and their teaching. Faculty satisfaction with classroom facilities was lower than with research facilities, with female faculty especially adamant that improvements in acoustics, lighting, and temperature control are needed.

White male faculty were most likely to view their courseload as too heavy and least likely to see their teaching as contributing "a great deal" to their professional development. The majority of white male and female faculty define their role interests as leaning toward or heavily toward research, while almost half of the minority faculty view teaching and research as equal and complementary roles (Table 2 ). ${ }^{1}$ All faculty were, however, less

\footnotetext{
${ }^{1}$ Note that findings suggest a much more prevalent research orientation among female faculty than often reported in the literature. While results undoubtedly reflect a bias in the sample due to the nature of the institution, they also suggest that more recent cohorts of women faculty may feel greater accord with the research mission of the university.
} 
than moderately satisfied with institutional rewards for teaching. When asked to rate the real and ideal importance of various criteria for tenure, for instance, faculty ratings of teaching were widely discrepant, with all three groups assigning a higher ideal value to teaching than they believe it is ascribed in reality (Table 3 ).

Service. Time estimates provided by faculty (Table 1) indicated that faculty tend to spend about a quarter of their time on service. Estimates for minority faculty were higher, but not significantly so. Other studies have similarly failed to find significant differences in the distribution of professional time by race (Elmore \& Blackburn, 1983; Silver et al., 1988). Nevertheless, the overall pattern of time distribution for each of the three groups is revealing. Of all faculty, minority members demonstrate the most even

TABLE 2

Role Interests: Research vs. Teaching

White Male Minority White Female

Role Interests:

Heavily toward research

Both, lean toward research

Both, equal \& complementary

Both, lean to teaching

Heavily toward teaching

Other

$\begin{array}{rrr}43 \% & 26 \% & 36 \% \\ 19 \% & 4 \% & 20 \% \\ 26 \% & 47 \% & 24 \% \\ 2 \% & 9 \% & 13 \% \\ 7 \% & 11 \% & 7 \% \\ 2 \% & 4 \% & \end{array}$

TABLE 3

Mean Ratings* of Real and Ideal Importance for Tenure

\begin{tabular}{|c|c|c|c|c|c|c|}
\hline & \multicolumn{2}{|c|}{ White Males } & \multicolumn{2}{|c|}{ Minority } & \multicolumn{2}{|c|}{ White Females } \\
\hline & Real & Ideal & Real & Ideal & Real & Ideal \\
\hline Research-publications & 4.83 & 4.36 & 4.86 & 4.50 & 4.94 & 4.50 \\
\hline Teaching & 3.25 & 4.17 & 3.70 & 4.55 & 3.48 & 4.18 \\
\hline Dept./university service & 2.38 & 2.79 & 2.83 & 3.40 & 2.34 & 2.87 \\
\hline
\end{tabular}


distribution of time across research, teaching, and service categories, and white men the least. Evidence suggests that minority faculty feel a deep level of commitment to both teaching and research and derive substantial satisfaction from both. It remains unclear, however, whether minority faculty feel, as is often assumed, a high level of commitment to service, whether they are simply asked to take on more service responsibilities, or whether both factors influence their choices.

Minority faculty were no more likely than other faculty to volunteer for a committee (about half never volunteer) and only a third of minority and 7\% of women reported serving primarily to represent a feminist or minority viewpoint. Nevertheless, minority faculty, and to a lesser extent white women, are more likely to serve on a much wider range of committees than white men.

Approximately $70 \%$ of minority and women faculty reported having been asked to sit on a committee at least once because of their gender or race. Minorities', and to a lesser extent, women's participation in service appears in large part to be the product of an institutional desire to have a diverse set of viewpoints represented in decision-making bodies. Once engaged in service, however, women and minority faculty were more likely than white male faculty to perceive the work as being very productive.

White male faculty appeared to participate in departmental committees and in the types of professional service most closely allied with individual research, e.g., grant review, and reviewing and editing for professional journals. White women were as heavily involved in refereeing journals as men, but not as involved in grant review. Minorities were somewhat less involved in both.

In summary, findings with regard to research, teaching, and service suggest that the most salient differences among the three faculty groups may be in the attitudes they hold. Minority faculty and to some extent female faculty were more likely to place a higher value on teaching, to view their teaching load as an appropriate and productive part of their professional lives, and to believe their service commitments had, in general, contributed to the growth and well-being of the university. On the other hand, women and minority members were more often asked to participate on committees, but no more likely to volunteer than white male faculty. Nor were minority or women faculty likely to allow their research programs to fall into serious neglect to make time for teaching and service. These results are not surprising given that a research university faculty is preselected for ability and interest in research, but do conflict with many commonly held notions about women and minority faculty and their commitment to research. 
All three groups of faculty tended to rate research and teaching as ideally of the greatest importance in tenure decisions (with service being less important), reflecting a general consensus among faculty about the goals of the university and their own professional priorities (Table 3). All three faculty groups felt that teaching is currently undervalued by the university, and minority faculty (who carry the heaviest service load) felt service should weigh more heavily, though still only moderately, in tenure criteria.

\section{Career commitment and job satisfaction}

Given evidence that women and minorities often lack role models, background and even institutional support for their academic careers, the question of whether they feel less commitment to their careers, and experience less job satisfaction, is a serious one (Baldridge, Curtis, Ecker, \& Riley, 1978; Finkelstein, 1984; Rausch, Ortiz, Douthitt, \& Reed, 1989).

Findings indicated that virtually all faculty who attain tenure-track positions at a major research university have and maintain a high level of commitment to an academic career. Women and minority faculty were somewhat more likely than white male faculty to experience a shift in the nature of their commitment, however, with a greater current emphasis on research. Whereas most faculty would choose their position again given the opportunity, women and minority faculty were more hesitant than white male faculty to recommend their position to a student or colleague if that person was a woman or member of a minority. Women and minority faculty felt their academic careers and whatever success they had attained were the products of a keen personal interest in their work and their own intrinsic motivation to succeed. Overall data suggest that, despite substantial satisfaction, minority and women faculty remain aware of the personal costs associated with attaining and maintaining their present positions. Although faculty agreed that the campus environment for women and minorities could be improved, no one faculty group appeared significantly more inclined to leave the university than any other. Still, slightly over a third of all faculty described themselves as "somewhat" or "very likely" to seek a new position in the next year.

Global ratings of job satisfaction were consistently strong across the three faculty groups. By and large, faculty were satisfied with their relations with colleagues, their participation in department decision-making, and their recognition within their discipline. Satisfaction with salary was below moderate, and satisfaction with fringe benefits was somewhat above. As in recent studies at other universities, the greatest dissatisfaction was with university 
recognition and support, and participation in university decision-making (Carnegie Foundation, 1989; Russell et al., 1990).

Questions about which aspects of academic life faculty find most satisfying and which they find most successful revealed an interesting and important pattern of response. Almost half of white male faculty tended to think of their research as both the most successful and the most satisfying part of their academic lives. In contrast, women and minorities were more likely to distinguish between research as the area of greatest success and other aspects of their academic career as most satisfying (e.g., teaching, students, collegiality).

One possible interpretation of this finding is that minorities and women may simply be more attuned to the satisfactions that come from the more immediate and interpersonal rewards of teaching, students, and colleagues, whereas it is more difficult for men, given their socialization and training, to separate satisfaction and success at a global level. Of the three groups, white women were the most satisfied with the intrinsic rewards of an academic career-the sense of autonomy, accomplishment, and the intellectual opportunities and challenge.

Contrary to what might be expected from the literature, minority and women faculty were as likely as white male faculty to exhibit high levels of commitment and satisfaction. At the same time, important between-group differences underlie the similarities. Women and minorities were as committed to an academic career and to the university as other faculty, but remained cognizant of the difficulties encountered and overcome as nontraditional members of the academic community. Similarly, minority and women faculty demonstrate strong job satisfaction, but are more likely than white male faculty to distinguish between the satisfactions associated with teaching, students, and colleagues, and the success of their research, than white male colleagues.

\section{Balance between work and personal life}

Research suggests that both women and minorities experience greater conflict due to the demands of work and nonwork roles than do white male faculty (Aisenberg \& Harrington, 1988; Justus et al., 1987; Rausch et al. 1989; Simeone, 1987). Women's childcare and household responsibilities and minority members' ties to their ethnic and racial communities constitute a complex set of demands. By and large, our study demonstrated the same kinds of conflicts for women and underrepresented minorities as found elsewhere. However, white male faculty appeared to be as affected by 
work-nonwork conflicts as white women, with more negative consequences for both work and personal life for white men than for any other group.

In this study, a much greater proportion of white male faculty than other faculty were married. In addition, almost a third of white male faculty reported having a spouse who chose not to be employed outside the home, as compared with $4 \%$ to $8 \%$ of other faculty.

Married faculty and those with young children appeared to experience one set of stresses and strains, while single faculty experience another. Single faculty said that long hours of work, a limited set of social contacts, and a community oriented toward families made for an extremely lonely lifestyle. Several faculty felt the problem to be severe enough to consider seeking a position elsewhere. Minority faculty indicated that because of the small minority community in the area, their career had had significant costs in terms of social relationships, including serious relationships and dating. Married faculty, on the other hand, often faced the difficult problem of finding suitable employment for a spouse. Faculty with young children were also concerned about the availability of quality childcare and what they considered to be the low level of local schools.

Overall findings suggested that minority faculty are more likely to distinguish between personal and professional parts of their life and to become engaged in the life of the community around them. In general, minority members seem more satisfied than other groups with the balance they have struck between the two significant domains of their life. At the same time, it is important to recognize that because of heavy workloads and a small minority community, many minority faculty have made substantial sacrifices in their personal and social life to remain at the university.

White women feel acutely the conflict between personal and professional life. Women appeared to have substantial responsibilities at home, with about half reporting that their personal commitments affect or interfere with career development. A review of the data, suggested, however, that the substantial personal and intellectual satisfaction women derive from their work offsets at least some of the costs and stresses incurred. These findings may help explain why examinations of research productivity in female academics have failed to show expected differences by marital and parental status (Finkelstein, 1984, p. 213; Simeone, 1987, pp. 123-5).

The data on white male faculty are somewhat more difficult to interpret and may reflect the awkwardness many men feel as their roles change vis-a-vis spouses or partners and children. Though white males' involvement with community or family was less clear, they were the group most likely to perceive the reciprocal effects of work and nonwork as negative. Moreover, 
white men were least satisfied with the balance between their personal and professional life and found balancing work and personal life as stressful as women did and more stressful than minorities did. It may be that changing expectations of men in the personal and social domain do not mesh well with the faculty model they were socialized to approximate and which still obtains. If so, the future would seem to hold more issues of balance, requiring more personal resources and individual innovation, and ultimately institutional policies and programs that will effectively supplement individual efforts.

\section{Recommendations}

The present study suggests that change may be crucial in several areas of academic life, including teaching and service. In addition, policy makers need to consider aspects of academic life and even nonwork life that are not part of a faculty member's formal professional responsibilities, but which affect those responsibilities. Recommendations made by faculty across campus were broad in scope, and the following discussion only covers a subset of the actual proposals made. Many of the recommendations provide useful suggestions for teaching and faculty development, relating to issues varying from faculty recruitment to methods of helping better coordinate work and nonwork life.

Recruiting women and minority faculty. Our research clearly indicated that most minority faculty are recruited through personal contacts. Departments committed to increasing the numbers of women and minorities in their fields will need to make more systematic efforts to pursue contacts at professional meetings, to inquire from colleagues at other universities about senior women and minority graduate students, and to provide funds for potential candidates from traditionally underrepresented groups to visit the university. Some universities are inviting promising young minority graduate students close to completing their degree to spend a semester on their campuses. These programs hope to recruit talented candidates to tenure-track positions.

Helping new faculty adjust. More mentoring of new faculty needs to take place both formally and informally. This is particularly true for women and minority faculty who, in general, receive less social support and who have fewer role models. A two-tiered system of mentoring is suggested: a one-on-one program of mentoring within departments and a series of seminars on topics of concern to untenured faculty sponsored by the Office of Faculty Development. Faculty development seminars would cover general organizational/professional issues (e.g., grantsmanship, institutional structure, procedures and criteria for tenure and promotion, coordinating work 
and nonwork life). Senior colleagues would then provide more specific information about departmental structure and expectations and help junior faculty shape a successful program of teaching and research.

All faculty felt that travel to professional conferences is critical to professional development and that present funding levels are inadequate. It is recommended that more generous reimbursement packages be made available, especially at the junior level.

Teaching responsibilities. Despite differences in the emphasis the three groups placed on teaching and research, virtually all faculty felt that teaching should be given more weight in tenure and review decisions. Numerous suggestions were made for increasing faculty satisfaction with teaching, and for communicating greater support for the teaching enterprise. Here are five areas suggested by respondents toward which any program of faculty or teaching development should be oriented: (1) help create evaluation criteria that allows excellent teaching to be better identified and rewarded (e.g., include peer and self-evaluations of teaching); (2) create forums for exchange about teaching so that recognized excellent teachers work with junior colleagues, for example, through team teaching or mentoring; (3) work with departments that now give greater rewards to research to bring teaching back into balance; (4) encourage administration to give all new teachers a one course reduction in load to be spent working with an experienced colleague or Teaching Resources consultant developing course materials and teaching skills; (5) encourage departments to make greater efforts to provide female faculty with opportunities for teaching graduate courses.

Service. All three faculty groups, including white male faculty, perceived women and especially minority faculty as carrying a heavier service load. There appear to be two ways of dealing with this problem, i.e., to reduce the amount of service requested or to give greater credit for service work at review time. Several faculty suggested developing guidelines concerning the number of committee assignments and overall time investment in service obligations asked of faculty.

Administration. One of the most widely endorsed recommendations was to promote greater numbers of women to leadership positions within the university. Such an initiative was seen as part of a larger, more active program of affirmative action-starting with recruiting women and minority faculty and providing adequate guidance and support for tenure and promotion. Indiana University recently sponsored a university-wide symposium on "Women in Administration and Management" to encourage more women to consider a career in administration and to serve as a tangible symbol of the University's commitment to women's advancement. Chancellors and deans 
enthusiastically supported the effort by encouraging women from their units to attend.

Collegial relations. Even when formal barriers to a career and professional achievement no longer exist, many informal ones often remain. Some of the most salient and poignant barriers according to women and minority faculty are social in nature: never being invited to lunch or informal gatherings where department business is discussed or failing to have one's views recognized in committees or faculty meetings (see also Rausch et al., 1989; Simeone, 1987). Again, it is important to note a general trend in recent research findings suggesting decreased satisfaction with the level of collegiality. Clearly, there is no easy remedy for such a situation. Respondents suggested that the university expand its support for faculty seminars (e.g., multidisciplinary seminars) and even promote diversity and collegiality as seminar themes. Other university-supported symposia that address issues of concern to women and minority faculty might also encourage social exchange and the formation of informal support groups.

The best antidote for deteriorating collegial relations, however, is department-level efforts to create and maintain an atmosphere of openness, encouragement, and productivity. As part of its Faculty Development Program, the Office for Academic Affairs at Indiana University has recently instituted a series of department-based grants that would provide a department with up to $\$ 20,000$ to help it articulate and achieve goals, remedy shortcomings, and enhance the sense of coherence and collegiality within the department. Departmental response has been overwhelmingly positive, and interestingly, proposals have focused almost entirely on the enhancement of curriculum and teaching in the department.

Coordinating work and nonwork. Regardless of differences in the specific nature of the conflict between professional and personal life for married and single faculty, the magnitude of the problem appears great. Furthermore, the balance between work and nonwork has implications not only for the individual but for the institution as well, i.e., in terms of morale, productivity, and retention. The kinds of programs that would most assist married faculty appeared to be a spouse employment assistance program, a family leave policy, and expanded childcare facilities. (Far from being a women's issue, work-family conflicts were as salient for men as for women.) Though somewhat different in nature from the types of programs just proposed, faculty also indicated that a more flexible "cafeteria style" benefit package would relieve some of the tensions associated with balancing familial and work roles. 
Again, as part of its Faculty Development efforts, the Office for Academic Affairs at Indiana University has begun to work on a variety of institutional programs to help ease some of the conflicts between a successful academic career and the demands of professional life. Since completing the study, the university has instituted the Partner Employment Assistance Program to help faculty partners find employment in the local area. In its first year, the Program has worked with 27 partners and found employment for almost half of them, with another $10 \%-15 \%$ currently interviewing for positions. Additionally, a brochure has been developed to help academicallyqualified faculty partners locate and apply for self-subsidizing grant funds through university channels. The administration is currently reviewing a Family Leave Policy for both faculty and staff, and university-sponsored childcare facilities may be expanded over the two years as space from an adjoining public school is vacated.

Single faculty and minority faculty were more likely than other groups to report feeling isolated in a small, "family-oriented" town. One proposal that would both help recruit faculty, especially minority faculty, and facilitate their integration into the local area is to charge a committee or office with responsibility for establishing contacts with organizations, churches, and other key groups in the community. This information could then be used by departments in their recruiting efforts. Optimally, faculty with similar interests would help introduce new colleagues to groups and activities in the community.

In conclusion, our research revealed that minority, white male, and white female faculty overlap broadly in their expectations, goals, and achievements. At the same time, it was also clear that the contributions of different faculty groups to their departments, disciplines, and university vary in important ways, and that this diversity of talents and interests is fundamental to the vitality of the academic community. Thus, although it is critical that all faculty strive for excellence in teaching and research, standards of excellence and routes to its attainment are enriched by differing perspectives. We are only now becoming aware of many of the hidden costs incurred through too exclusive a reliance on any one faculty model. The challenge ahead is to rethink and respond in such a way that all faculty are encouraged to perform to their fullest.

\section{References}

Aisenberg, N., \& Harrington, M. (1988). Women of academe: Outsiders in the sacred grove. Amherst, MA: University of Massachusetts Press. 
Baldridge, J. V., Curtis, D. V., Ecker, G., \& Riley, G. L. (1978). Policy making and effective leadership. San Francisco: Jossey-Bass.

Bowen, H. R., \& Schuster, J. H. (1986). American professors: A national resource imperiled. New York: Oxford University Press.

Carnegie Foundation for the Advancement of Teaching. (1990). Women faculty excel as campus citizens. Change, 22, 39-50.

Carnegie Foundation for the Advancement of Teaching. (1989). The condition of the professoriate: Attitudes and trends, 1989. Princeton, $\mathrm{NJ}$ : Author.

Clark, S., \& Corcoran, M. (1986). Perspectives on the professional socialization of women faculty: A case of accumulative disadvantage? Journal of Higher Education, 57, 20-43.

Elmore, C., \& Blackburn, R. T. (1983). Black and white faculty in white research universities. Journal of Higher Education, 54, 1-15.

Finkelstein, M. J. (1984). The American academic profession. Columbus, $\mathrm{OH}$ : Ohio State University Press.

Justus, J. B., Freitag, S. B., \& Parker, L. L. (1987). The University of California in the twenty-first century: Successful approaches to faculty diversity. Berkeley, CA: University of California.

Lomperis, A. M. T. (1990). Are women changing the nature of the academic profession? Journal of Higher Education, 61, 643-677.

Menges, R. J., \& Exum, W. H. (1983). Barriers to the progress of women and minority faculty. Journal of Higher Education, 54, 123-144.

Rausch, D. K., Ortiz, B. P., Douthitt, R. A., \& Reed, L. L. (1989). The academic revolving door: Why do women get caught? CUPA Journal, 40, 1-16.

Russell, S. H., Cox, R. C., Williamson, C., Boismeier, J., Javitz, H., Fairweather, J., \& Zimbler, L. J. (1990). Faculty in Higher Education Institutions, 1988. (NCES Report 90-365) Washington, DC: U.S. Department of Education, National Center for Education Statistics.

Silver, J. H., Dennis, R. W., \& Spikes, C. (1988). Black faculty in traditionally white institutions in selected Adams States: Characteristics, experiences and perceptions. Atlanta, GA: Southern Education Foundation.

Simeone, A. (1987). Academic women: Working towards equality. MA: Bergin \& Garvey.

Sorcinelli, M. D. (1988). Satisfactions and concerns of new university teachers. In J.Kurfiss, L. Husen, S. Kahn, M. D. Sorcinelli, \& R. G. Tiberius (Eds.), To Improve the Academy, 7, 121-133.

Sorcinelli, M. D., \& Gregory, M. (1987). Faculty stress: The tension between career demands and "having it all". In P. Seldin (Ed.), Coping with faculty stress (pp. 43-52), 29, New Directions for Teaching and Learning. San Francisco: Jossey-Bass. 